\title{
PENGARUH AROMA TERAPI LEMON TERHADAP PENURUNAN RASA NYERI PADA PASIEN POST SECTIO CAESAREA DI RUMAH SAKIT UMUM IMELDA PEKERJA INDONESIA MEDAN TAHUN 2018
}

\author{
${ }^{1}$ Rostinah Manurung, ${ }^{2}$ Era Noviya \\ ${ }^{1}$ Dosen Prodi S1Keperawatan, STIKes Imelda, Jalan Bilal Nomor 52 Medan; \\ ${ }^{2}$ Alumni STIKes Imelda \\ E-mail: rostinahmanurung@gmail.com
}

\begin{abstract}
ABSTRAK
Sectio caesarea adalah persalinan melalui sayatan pada dinding abdomen dan uterus yang masih utuh dengan berat janin lebih dari $1000 \mathrm{gr}$ atau umur kehamilan $\geq 28$ minggu. Aromaterapi lemon merupakan jenis aromaterapi yang dapat digunakan untuk mengatasi nyeri dan cemas.Zat yang terkandung dalam lemon salah satunya adalah linalool yang berguna untuk menstabilkan system saraf, sehingga dapat menimbulkan efek tenang bagi siapapun yang menghirupnya. Penelitian ini bertujuan untuk melihat pengaruh dari aromaterapi lemon terhadap penurunan nyeri pada pasien Sectio caesarea di rumah sakit Umum Imelda Pekerja Indonesia Medan. Rancangan penelitian ini quasi experiment dengan pendekatan pre-test dan post testwith control group.Populasi dalam penelitian ini adalah 1.150 orang di Rumah sakit Umum Imelda Pekerja Indonesia Medan dan sampel sebanyak 30 orang yang ditentukan dengan menggunakan tehnik accidental sampling.Analisis statistic yang digunakan uji Mc Nemar. Hasil analisis univariat mayoritas responden mengalami penurunan rasa nyeri sebanyak 25 orang (83,33\%) sedangkan yang mengalami peningkatan rasa nyeri sebanyak 5 orang $(16,67 \%)$. Hasil analisis bivariate uji MC Nemar P=0,002 ( $<0.005)$ artinya ada pengaruh aroma terapi lemon terhadap penurunan nyeri post section caesarea. Diharapkan perawat agar dapat mengaplikasikan aromaterapi lemon terhadappenurunanrasa nyeri post section caesarea.
\end{abstract}

Kata Kunci : Aromaterapi Lemon, Nyeri, Sectio Caesarea

\section{PENDAHULUAN}

Persalinan adalah suatu proses Merangsang sensori dan mempengaruhi organ lainnya sehingga dapat menimbulkan efek terhadap emosi. Aromaterapi ditangkap oleh reseptor dihidung, Kemudian memberikan informasi lebih jauh di otak yang mengontrol emosi dan memori serta memberikan informasi ke hipotalamus yang merupakan pengatur sistem internal tubuh, sistem seksualitas, suhu tubuh, dan reaksi terhadap nyeri (Hale, 2008).

Menurut Word Healt Organitation (WHO) Negara tersebut diantaranya adalah Australia (32\%), Brazil (54\%), dan Colombia (43\%). Angka kejadian sectio caesarea di Indonesia tahun 2005 sampai dengan 2011 rata-rata sebesar $7 \%$ dari jumlah semua kelahiran, sedangkan pada tahun 2006 sampai dengan 2012 rata-rata kejadian sectio caesarea meningkat menjadi sebesar $12 \%$ (WHO, 2014). WHO menganjurkan operasi caesarea hanya sekitar 10-15\% dari jumlah kelahiran. Anjuran WHO tersebut tentunya didasarkan pada analisis resiko-resiko yang muncul akibat sectio caesarea baik resiko bagi ibu maupun bayi (Sudiharjani, 2010).

Menurut Data statistik pada tahun 2000 dilaporkan di dunia wanita melahirkan dengan sectio caesarea meningkat 4 kali dibandingkan 10 tahun sebelumnya, dimana di Amerika Serikat persalinan dengan sectio caesarea sebanyak 35\% dari seluruh persalinan, Australia 35\%, Skotlandia 43\% dan Dari data peneliti terdahulu terdapat bahwa Tindakan sectio caesarea $(S C)$ dapat menyebabkan nyeri dan mengakibatkan terjadinya perubahan kontinuitas jaringan karena adanya pembedahan. Ketidaknyamanan yang dirasakan pasien pasca sectio caesarea $(S C)$ dapat menyebabkan resiko komplikasi pada bayi maupun pada ibu (Whalley, 2008). Penanganan yang sering digunakan untuk menurunkan nyeri pasca sectio caesarea $(S C)$ 
berupa penanganan farmakologi. Kombinasi secara farmakologi untuk mengontrol nyeri dengan farmakologi agar intensitas nyeri dapat berkurang serta masa pemulihan tidak memanjang (Bobak, 2004).Metode non farmakologi bukan merupakan pengganti farmakologi.Tindakan tersebut diperlukan untuk mempersingkat episode nyeri. Mengkombinasikan metode nonfarmakologi dan farmakologi adalah cara yang efektif untuk mengontrol nyeri. Manajemen non farmakologi yang biasa digunakan salah satunya adalah dengan menggunakan aromaterapi (Sulistyowati, 2013). Aromaterapi adalah terapi menggunakan essential oil atau sari minyak murni untuk membantu memperbaiki atau menjaga kesehatan, membangkitkan semangat, gairah, menyegarkan serta menenangkan jiwa, dan merangsang proses penyembuhan (MacKinnon, 2004).

Angka kejadian sectio caesarea di Indonesia menurut data survey Nasional pada tahun 2007 adalah 921.000 persalinan atau sekitar 22,8\% dari seluruh persalinan pengeluaran hasil konsepsi yang dapat hidup dari dalam uterus melalui vagina ke dunia luar (Prawihardjo dkk, 2007 dalam Ai Yeyeh dkk,2014). Sedangkan persalinan normal adalah pengeluaran janin yang terjadi pada kehamilan yang cukup bulan (37-42 minggu) lahir spontan dengan presentasi belakang kepala yang berlasung dalam 18 jam, tanpa komplikasi pada ibu maupun pada janin (Wiknjosastro dalam Ai Yeyeh dkk, 2014). (Rasjidi, 2009). Hasil Riset Kesehatan Dasar (Riskesdas) tahun 2013 menunjukkan kelahiran bedah sesar sebesar 9,8\% dengan provinsi tertinggi di DKI Jakarta $(19,9 \%)$ dan terendah disulawesi Tenggara $(3,3 \%)$.

Mekanisme kerja aromaterapi dalam tubuh manusia berlangsung melalui dua sistem fisiologis, yaitu sirkulasi tubuh dan sistem penciuman. Wewangian dan akhirnya mempengaruhi organ lainnya sehingga dapat menimbulkan efek yang kuat terhadap emosi. Aromaterapi ditangkap oleh reseptor dihidung, kemudian memberikan informasi lebih jauh karena di otak yang mengontrol emosi dan memori serta memberikan informasi ke hipotalamus yang merupakan pengatur sistem internal tubuh, sistem seksualitas, suhu tubuh, dan reaksi dapat mempengaruhi kondisi psikis, daya ingat, dan emosi seseorang (Anggorowati, 2007).

Menurut WHO ( World Health Organization), memperkirakan bahwa angka persalinan dengan sectio Caesar $10 \%$ sampai $15 \%$ dari semua proses persalinan dinegara Negara berkembang dibandingkan dengan 20 $\%$ Britania raya, $23 \%$ di Amerika Serikat dan kanada pada 2003 memiliki angka $21 \%$ (Juditha, 2009).Menurut World Health Organization (WHO) tahun 2015 sebnyak 99 $\%$ kematian ibu akibat masalah persalinan atau kelahiran yang terjadi di negara-negara berkembang. Rasio kematian ibu di negaranegara berkembang merupakan yang tertinggi dengan 450 kematian ibu/100.000 kelahiran bayi hidup, jika dibandingkan dengan kematian ibu dengan Sembilan Negara maju dan 51 negara persemakmuran.

Dari tahun ke tahun angka kejadian sectio caesarea terus meningkat. Angka persalinan melalui sectio caesarea di Amerika Serikat telah meningkat empat kali lipat, dari 5,5 / 100 kelahiran pada tahun 1970 menjadi 22,7 per 100 kelahiran pada tahun 1985.Selain itu angka kejadian sectio caesarea di Australia pada tahun 1998 sekitar 21\% dan pada tahun2007 sekitar 31\%. DiIndonesia angka kejadian sectio caesarea mengalami peningkatan pada tahun 2000 2006 sebesar $48,85 \%$ dan pada tahun 20112013 sebesar 49,6\% (Kulas, 2008).

Selain itu angka kejadian sectio caesaria di Indonesia Angka Kematian Ibu (AKI) di Indonesia pada tahun 2007 sebesar 228/100.000 kelahiran hidup.Angka ini lebih rendah dibandingkan AKI hasil SDKI tahun 2002-2003- dari yg terbaru yang mencapai 307/100.000 kelahiran hidup.Sedangkan di Propinsi DIY kematian ibu dalam 4 tahun terakhir menunjukkan penurunan yang cukup baik. Tahun 2008 AKI di DIY berada pada angka 104/100.000 menurun dari $114 / 100.000$ pada tahun 2004. Sementara target MDGs AKI turun menjadi 102/100.000 kelahiran hidup pada tahun 2015 (Depkes RI, 2009).Sedangkan angka kematian bayi 
(AKB) berhasil di turunkan secara tajam dari 68 / 1000 kelahiran hidup pada tahun 1990 an menjadi 34 / 1000 (Kemenkes, 2010).

Berdasarkan hal itu Indonesia mempunyai komitmen untuk menurunkan angka kematian ibu (AKI) menjadi 102/100.000 kelahiran hidup, angka kematian bayi (AKB) dari 68 menjadi 23/100.000 dan angka kematian balita (AKABA) 97 menjadi 32/100.000 kelahiran hidup pada tahun 2015. Berdasarkan Survey Demografi Kesehatan Indonesia (SDKI) pada tahun 2011 angka kematian ibu di Indonesia tercatat 226 orang/100.000 kelahiran hidup.Angka tersebut lebih rendah dari angka kematian ibu (AKI) ditahun sebelumnya tercatat mencapai 300 orang/10.000 kelahiran hidup.Angkaangka diatas masih menunjukkan bahwa angka kematian ibu (AKI) di Indonesia masih cukup tingi walaupun dari tahun ke tahun terdapat penurunan. Penyebab langsung kematian ibu $90 \%$ terjadi pada saat persalinan (survey kesehatan rumah tangga, 2001) penyebab langsung kematian ibu adalah perdarahan $28 \%$, ekslamsi $24 \%$, infeksi $11 \%$, partus lama $5 \%$, dan abortus 5 $\%$, penyebab tidak langsung kematian ibu antara lain kurang energy kronis pada kehamilan $37 \%$ dan anemia pada kehamilan $4 \%$.

Berdasarkan data yang ada dari Rumah Sakit Umum Imelda Pekerja Indonesia Medan angka Post Sectio Caesarea pada tahun 2017 jumlah pertahun yaitu mencapai 1.150 pasien, dan dalam 1 bulan pasien Post Sectio Caesarea di Rumah Sakit Imelda Pekerja Indonesia Medan yaitu sejumlah 96 pasien. Berdasarkan latar belakang diatas, maka penulis tertarik untuk meneliti permasalahan tersebut dengan judul “ Pengaruh Aromaterapi Lemon Terhadap Penurunan Nyeri pada Pasien Sectio Caesaria di Rumah Sakit Imelda Pekerja Indonesia Medan tahun 2018.

\section{Identifikasi Masalah}

a. Bagaimanakah pengetahun responden tentang pemilihan aromaterapi lemon bagi penurunan nyeri pada Sectio Caesarea? b. Bagaimanakah pengetahuan keluarga tentang aromaterapi lemon bagi penurunana nyeri adalah keputusan yang baik?

c. Bagaimanakah pengetahuan keluarga tentang resiko jika tidak diberikan aromaterapi lemon pada nyeri pasien Sectio Caesarea?

d. Apakah yang menjadi factor penyebab responden akan lebih memilih aromaterpi lemon untuk menurunkan nyeri pada Sectio Caesarea?

\section{Rumusan Masalah}

Bedasarkan latar belakang diatas rumusan masalah adalah 'Apakah pengaruh aroma terapi lemon dapat menurunkan nyeri pada pasien Sectio Caesarea di Rumah Sakit IPI Imelda Medan?

\section{Tujuan Penelitian}

Tujuan Umum

Adapun tujuan umum dalam penelitian adalah untuk mengetahui pengaruh dari aromaterapi lemon terhadap penurun nyeri pada pasien Sectio Caesareadi RSU IPI Medan.

Tujuan Khusus

a. Mengetahui pengaruh aroma terapi Lemon terhadap ideal diri pasien SC di RSU IPI Medan .

b. Mengetahui pengaruh efek samping aromaterapi lemon terhadap citra diri pasien Sectio Caesareadi RSU IPI Medan.

\section{Manfaat Penelitian}

1. Bagi Profesi Keperawatan

Sebaiknya dapat dijadikan sebagai bahan pertimbangan bagi perawat untuk memberikan asuhan keperawatan pada pasien post Sectio Caesareadengan memberikan aromaterapi lemon.

2. Bagi Peneliti

Penelitian ini dapat menjadi informasi tentang pengaruh aromaterapi lemon terhadap penuruna rasa nyeri Sectio Caesarea sehingga menjadi sumber informasi bagi peneliti untuk memberikan asuhan keperawatan dengan lebih baik. Pelayanan 
Keperawatan dengan penelitian ini diharapkan pelayanan keperawatan bukan hanya memberikan terapi farmakologis dalam mengatasi nyeri post sectio caesarea pada ibu post sectio caesarea, namun dapat memberikan terapi komplementer yang berupa aromaterapi lemon untuk menangani nyeri post sectio caesarea dalam melaksanakan perannya sesuai prosedur yang ada.

3. Bagi pasien

Membantu mengatasi dan mengurangi rasa nyeri pada pasien yang cendrung merasakan nyeri yang berlebihan dan mengatasi mekanisme sehingga pasien mampu menjalani hidup dengan tenang.

4. Bagi Masyarakat

Sebagai bahan masukan dan membantu program promosi kesehatan untuk penyuluhan aromaterapi lemon untuk prnurunan nyeri pada Sectio Caesarea.

5. Bagi Rumah Sakit Imelda Pekerja Indonesia Medan

Hasil penelitian ini sebaiknya dijadikan / menjadikan sebagai masukkan informasi bagi rumah sakit tentang menggunakan pengobatan non farmakologi dalam mengurangi nyeri post sectio caesarea dan diaplikasikan pada pasien lain yang mengalami nyeri.

6. Bagi institusi pelayanan

Rumah sakit beserta jajarannya perlu mengetahui bagaimana cara mengurangi nyeri pasien Sectio Caesaria yang menjalani Aromaterapi Lemon sehingga dapat dicari solusi terbaik untuk penurunan rasa nyeri pada pasien.

7. Bagi peneliti lain

Diharapkan penelitian pengaruh aromaterapi lemon terhadap penurunan nyeri, sehingga dapat dijadikan referensi bagi peneliti lain yang akan melakukan penelitian selanjutnya dengan intervensi yang berbeda.

\section{METODE}

\section{Desain Penelitian}

Jenis penelitian yang digunakan dalam penelitian ini yaitu suatu penelitian dengan melakukan percobaan yang bertujuan untuk mengetahui pengaruh yang timbul akibat adanya intervensi (Notoatdmojo, 2010). Desain penelitian yang digunakana dalah quasi experiment dengan pendekatan pretestand post-test design with control group, yaitu membandingkan subjek sebelum dan sesudah diberikan aromaterapi Lemon dalam penurunan nyeri Post Sectio Caesare kepada kelompok eksperimen dengan kelompok kontrol di Rumah Sakit Imelda Pekerja Indonesia Medan.

\section{Tempat Penelitian}

Penelitian ini akan dilakukan di Rumah Sakit Umum Imelda Pekerja Indonesia Medan

\section{Alasan penelitian}

Alasan penelitian ini di lakukan di Rumah Sakit Umum Imelda Pekerja Indonesia Medan karena merupakan Rumah Sakit milik yayasan imelda,yang merupakan RS rujukan dan sudah type B Sehingga diperkirakan akan mudah mendapatkan subjek penelitian. Jumlah pasien yang melahirkan secara sectio caesarea juga sangat tinggi yaitu 1.150 pasien / tahun.

\section{Populasi Penelitian}

Populasi dalam penelitian ini adalah semua pasien yang melahirkan dengan carasectio caesarea (SC) di Rumah Sakit Umum Imelda Pekerja Indonesia Medan. Dengan jumlah keseluruhan pasien berjumlah 1.150 pada tahun 2017 maka dari itu peneliti mengambil populasi dari jumlah rata-rata dengan jumlah 96 pasien per bulan.

\section{Sampel Penelitian}

Sampel penelitian ini adalah sebagian dari pasien yang melahirkan sectio caesarea di Rumah Sakit Umum Imelda Pekerja Indonesia Medan, Maka diperoleh populasi yang mewakili suatu populasi disebut sebagai sampel, (Saryono, 2013). Sehingga diperoleh sampel sebanyak 30 pasien yang ada.Pengambilan sampel dilakukan peneliti pada ruangan rawat inap di Rumah Sakit Umum Imelda Pekerja Indonesia Medan. 
mengalami peningkatan nyeri sebanyak 30 orang $(100 \%)$, sedangkan setelah melakukan aroma terapi lemon post sectio caesarea Post Test yang mengalami penurunan nyeri sebanyak 25 orang $(83,33)$ dan yang mengalami peningkatan sebanyak 5 orang $(16,67)$.

\section{Aroma Terapi Lemon}

Hasil uji statistika dengan menggunakan Mc Nemar di peroleh $p=0,002(>0,05)$ yang artinya adanya Pengaruh Aromaterapi Lemon Terhadap Penurunan Nyeri Post Sectio Caesarea di Rumah Sakit Umum Imelda Pekerja Indonesia Medan tahun 2018.

\section{KESIMPULAN}

1. Mayoritas responden yang diperoleh dari karakteristik dalam penelitian ini, yaitu usia responden 29-32 tahun (43,3\%), pendidikan $(46,6 \%)$ dan responden yang banyak tidak bekerja $(33,3 \%)$

2. Sebagian besar responden dalam penelitian ini yang mengalami penurunan pada tingkat nyeri $(83,33 \%)$ dan yang tidak mengalami penurunan nyeri $(16,67 \%)$ setelah melakukan aroma terapi lemon.

3. Uji Mc Nemaryang dilakukan diperoleh nilai $p=0,002(<0,05)$ artinya ada pengaruh aroma terapi lemon terhadap penurunan nyeri post sectio caecarea di Rumah Sakit Umum Imelda Pekerja Indonesia Medan.

\section{SARAN}

1. Bagi Institusi (STIKes Imelda Medan) Hendaknya mengadakan edukasi promosi kesehatan tentang penurunan nyeri dan salah satu caranya yaitu menggunakan aroma terapi lemon

2. Petugas kesehatan di Rumah Sakit Umum Imelda Pekerja Indonesia Medan

Diharapkan perawat agar dapat menginternalisasikan aroma terapi lemon terhadap penurunan nyeri post sectio cearea.

3. Bagi peneliti selanjutnya
Diharapkan untuk dapat melakukan penelitian selanjutnya dengan responden yang berbeda dan mengembangkan penelitian yang berkaitan dengan aroma terapi lemon terhadap penurunan nyeri post sectio cearea.

\section{DAFTAR PUSTAKA}

Anggorowati. (2007). Efektifitas pemberian intervensi spiritual ibu terhadap nyeri Post Sectio Caesarea (SC) pada RS Sultan Agung Semarang. Jurnal Media Ners I.

Asmadi. (2008). Tekhnikprosedural keperawatankonsep dan aplikasi kebutuhan dasar klien. Jakarta: Salemba Medika.

Asomoah. (2011). Distribution of cause of maternal mortality among different socio. Demographic groups in ghana; A Descriptive study.BMC publik health.

Cunningham, F.G. (2005). Obstetri Wiliams. Edisi 21. Jakarta: EGC

Hutasoit, A.S. (2002). Panduan praktik pijat Aroma Terapi Untuk Pemula. Jakarta: Garemedia Pustaka Utama.

Huck, B. (2010). Aromatherapy Science: A guide for health care profesionalis London. United kingdom: Pharmaceutical press

Jaelani. (2009). Aroma Terapi. Edisil. Jakarta: pustaka populer Obor.

Koensoemardiyah. (2009). Aromaterapi untuk Kesehatan, Kebugaran dan Kecantikan. Yogyakarta: Lily publisher Andi Offset.

Mackinnon. (2004). Aromatherapy a Practical Approach. United Kingdom: Scotprint.

Makhoul, S., Bakkour, Y., Nakat, H.E., Omar, F.E. (2012). The Lebanese Citrus aurantium: A Promising Future in Medicinal Phytochemistry. Journal of Pharmacognosy and Phytochemistry ISSN 2278-4136 ZDB-Number: 2668735-5 IC Journal No: 8192Volume 1 Issue 4 Online Available at:www.phytojournal.com

Namazi, M., Akbari, S.A.A., Mojab, F., Talebi, A., Majd.H.A., Jannesari, S. 
(2014). Effects of Citrus Aurantium (Bitter Orange) on the Severity of FirstStage Labor Pain.Iranian Journal of Pharmaceutical Research (2014), 13 (3): 1011-1018 Received: January 2014. Accepted: May 2014.

Sawamura, M., Son, U.S., Choi, H.S. (2004). Compositional changes in commercial lemon essential oil for aromatherapy. Int, J. Aromather. 14: 27-36.

Sulistyowati, Dina Indrati Dyah. (2009). Efektifitas Terapi Aroma Lavender terhadap Tingkat Nyeri dan Kecemasan Persalinan Primipara Kala I di Rumah Sakit dan Klinik Bersalin Purwokerto.

Manuaba I.B.G, (2010). Kapita Selekta Penatalaksanaan Rutin Obstetri Ginekologi dan KB, Jakarta : EGC.

Potter, P.A and Perry, A.G. (2010). Fundamentalsof nursing, Fundamental Keperawatan Edisi 7. Jakarta: Salemba Media.
Prawihardjo, S. dan Ai Yeyeh. Asuhan Kebidanan II Persalinan. Jakarta: EGC.

Setiadi. (2007). Konsep dan Penulisan Riset Keperawatan. Edisi Pertama. Yogjakarta: Graha Ilmu.

Wong. (2010). Easing anxiety with aromatherapy. About.com Alternatifemedecine [ Jurnal Online ]. Diperoleh tanggal 16 April 2018 dari

http://altmedicine.about.com/od/anxiety/a/anx iety_acupunc ture.htm

http://sugithewae.wordpress.com/2012/12/08/ teknik-sampling/24 Mei 2018/ sugiarbini/ teknik sampling

http://bangsalsehat.blogspot.com/2017/06/pen ilaian-skala-nyeri-pasien-skala.html/01 Juni 18/11:19

http://www.e-skripsi.stkesmuh-pkj.ac.id/eskripsi/index.php?p=fstream \&fid= 490\&bid=546/12/07/18/12:10

https://media.neliti.com/media/publications/7 0906efektifitas-aromaterapi. pdf/12/ 7/18/12:05. 